\title{
Serious Game Attributes for the Construction of a Hazard Identification Framework
}

\author{
https://doi.org/10.3991/ijim.v12i7.9647 \\ Norhazren Izatie Mohd( $\left({ }^{\varpi}\right)$, Kherun Nita Ali, \\ Ahmad Faiz Azizi Ahmad Fauzi, Shirin Shafiei Ebrahimi \\ Universiti Teknologi Malaysia, Johor Bahru, Malaysia \\ b-kherun@utm.my
}

\begin{abstract}
In recent years gaming products have increasingly been used to enhance learning and training development in the academic and commercial sectors. Gaming is an approach that applies technology to provide an almost real experience with interactive field training. It is an approach that supports the theory of learning by doing with a real case scenario. The purpose of this paper is to determine serious game attributes to support effective training using serious game approach. Through systematic literature review on eleven selected articles, nineteen game attributes were identified. Hence, based on the definition and description from the articles, text analyses were conducted to determine categories of attributes based on educational theories' perspectives. This study adopted the deductive content analysis approach which 14 relevant research articles between 1994 and 2016 were identified from the Web of Science and SCOPUS databases. It appears that serious game attributes according to the educational perspectives are being practised using various ideas, terms and concepts. Hence, the findings can be justified that serious game attributes are important to enhance the effectiveness of training modules. All these attributes will become part of the serious game framework for hazard identification training modules. The target is to deliver effective and active training module to construction-related workers.
\end{abstract}

Keywords - Game Attributes, Serious Game, Learning theory

\section{$1 \quad$ Introduction}

'Serious games' have increasingly been used to enrich learning and development for both commercial and academic purposes. A Google search on the term 'serious games' may yield almost over 1,090,000 results which shows that it is one of the trending terms on the Internet. Although the use of the term itself has already been established, there is yet a formal definition of the concept of 'serious game' as a training tool. In this study, serious game is defined as training tools that embrace game technology which aims to train decision making in handling hazard. Serious games can enrich learning and development in both commercial and academic sectors. The first concept of the serious game was explored by the US military when they utilised game technology as their military training delivery approach. Numerous injuries such as lodging, education, construction, oil and gas, and mining have applied the serious game as training delivery. 
A serious game is an affordable technology in designing a training module to train problem solving or decision-making which is too expensive or dangerous to be conducted in the real world. However, training using serious game may not be enjoyable because it is different from the normal game which focuses more on educational objectives, and not with entertainment. However, even without enjoyment, the learner can still learn and achieve the objective of playing it. The main advantages offered by the serious game is the ability to provide the simulation of real-life situations for training purposes i.e. environment, system, role-play scenario, etc. This ability will provide a new experience to the learner especially when the subject matter is too costly, too risky, or ethically unacceptable in the real world.

\section{The Game Attributes}

Serious games are referred to as the type of games when the focus of such games is for training, advertising, simulation or education. This is because when comparing serious games with other computer or video games, serious games are not only about the story, art and software, but they are beyond that. It has an addition of pedagogy which means that in serious games, there are activities related to education from which players gain knowledge and skills. However, pedagogy element must be supported by other elements such as art, story and entertainment. Therefore, in order to support the pedagogy elements in serious games, serious game attributes must be determined and integrate with the relevant theory of learning. In understanding the attributes of the serious game, specific attributes that establish this game are identified. Numerous researchers have contributed to the development of game attributes. The earliest work was found in 1981 when Malone identified four aspects as the basic building blocks of a game which are curiosity, fantasy, challenge, and control. After that the level of player control, task nature, and the role of the player as a related concept in designing a game was identified. Finally, aspects of conflict and closure were introduced by Thiagarajan in 1999. Additionally, few attributes which become fundamental to games are discovered which are rules, goals, contexts, player motivations and attachments to the goals.

In the following years, further research was conducted unifying the attributes by consolidating Malone's list. They have split up curiosity into two attributes namely sensory stimuli and mystery. Rules and goals attributes are added which originally generated from challenge attributes. Afterwards, findings were extensively reviewed. Researchers introduced twelve additional attributes in designing games including adoption, assessment, challenge, conflict, control, fantasy, interaction (equipment), interaction (interpersonal), interaction (social), language/ communication, location, mystery, progress and surprises, sensory stimuli, representation, safety, players, and representation.

However, other research indicated that new attributes are fraction from Malone characteristics. Hence, they suggested that some Wilson's attributes are related and can be grouped into categories, similar to the initial work. They listed the related fraction attributes according to the Malone characteristic, for example, the optimal level of difficulty (Wilson: adaption), performance feedback (Wilson: assessment), challenge 
(Wilson: Conflict) and control (Wilson: interaction equipment / interpersonal /social). Table 1 shows the list of modified game attributes. Document title and meta-data

Table 1. Modified list of game attributes

\begin{tabular}{|c|c|c|c|}
\hline \multicolumn{4}{|c|}{ Game Attributes } \\
\hline GA01 & Challange & GA11 & Interaction (social) \\
\hline GA02 & Control & GA12 & Language/communication \\
\hline GA03 & Role of player & GA13 & Location \\
\hline GA04 & Rule and Goal & GA14 & Mystery \\
\hline GA05 & Conflict & GA15 & Progress \\
\hline GA06 & Adaptation & GA16 & Surprises \\
\hline GA07 & Assessment & GA17 & Sensory Stimuli \\
\hline GA08 & Fantasy & GA18 & Representation \\
\hline GA09 & Interaction (Equipment) & GA19 & Safety \\
\hline
\end{tabular}

\subsection{Game attributes through educational perspectives}

The purpose of game attributes is to motivate and excite the users. However, for a game to become an effective educationally-serious game, the art of learning value should be combined with games. Therefore, to create meaningful and effective learning, the serious game should exhibit some of the following attributes in Table 2. Twelve attributes are identified which need to be adopted in designing serious game training modules. Hence, four basic theories of learning are used to extract attributes of the serious game in supporting effective learning.

Table 2. Twelve Serious Game Attributes through educational perspectives

\begin{tabular}{|l|l|l|l|}
\hline \multicolumn{1}{|c|}{ Theory } & \multicolumn{2}{|c|}{ Attributes } & \multicolumn{1}{c|}{ Description } \\
\hline \multirow{4}{*}{ Behaviourism } & SGA01 & Interaction & Engagement in learning \\
\cline { 2 - 4 } & SGA02 & Reward & Incentives for the learner \\
\cline { 2 - 4 } & SGA03 & Practice and drill & Learning activities and exercises within the game \\
\cline { 2 - 4 } & SGA05 & Linearity & $\begin{array}{l}\text { The learning material is delivered in an incremental } \\
\text { way }\end{array}$ \\
\cline { 2 - 5 } & SGA06 & Attention span & Learning is arranged sequentially \\
\cline { 2 - 4 } & SGA07 & Transfer of learnt Skilled & $\begin{array}{l}\text { Applying Skills to new learning based on previous } \\
\text { learning }\end{array}$ \\
\hline \multirow{5}{*}{ Constructivism } & SGA08 & Scaffolding & Support and help during the learning \\
\cline { 2 - 4 } & SGA09 & Learner control & $\begin{array}{l}\text { Self-learning and active learning based on learner } \\
\text { pace }\end{array}$ \\
\hline \multirow{3}{*}{$\begin{array}{l}\text { Experiential } \\
\text { Learning }\end{array}$} & SGA10 & $\begin{array}{l}\text { Accommodating the } \\
\text { learner's style }\end{array}$ & Learning process to suit of learner preferences \\
\cline { 2 - 4 } & SGA11 & Scenario-based learning & $\begin{array}{l}\text { Learning where the learner can relate what is being } \\
\text { learnt within the game to the outside world. }\end{array}$ \\
\cline { 2 - 4 } & SGA12 & Intermittent feedback & Just-in-time feedback for learning \\
\hline
\end{tabular}




\subsection{Methodology}

A deductive approach is based on an earlier theory or model and therefore it moves from general to specific. It only can be carried out when the structure of analysis is operationalized on the basis of previous knowledge. For this study, the content components that need to be analysed consist of phrases, concepts, theories and the characteristic which fall under objectivity outcome. This outcome only pursues the basic context, which the results obtained will remain the same from each document or message. Hence, for this study the deductive content analysis study was carried out onto the attributes of serious game which are ascertained through the review from previous studies. However, these attributes need to be categorised according to the educational view as a feature into the serious game framework. It is also important to conduct the content analysis as an approach for the researcher to make an observation about the implicit messages that are conveyed. Fourteen articles from the Web of Science and SCOPUS database were used to search the relevant research articles consisting of reports, journals and proceedings from 1994 to 2016. Even though the sampling size is small ranging from 6 to 12, it is enough to carry out content analysis study. After that, the data was extracted according to the text analysis, which will determine the frequency of predetermined coding mentioned in the articles. Besides that, interpretation of the text analysis was also conducted to extract and categorise the attributes according to the predetermined coding. Pre-determined coding was constructed according to the literature review. This code lead to the findings of the content analysis.

\subsection{Results and Discussion}

After analysing the content of the texts, twelve attributes were identified from four learning theories. From the analysis, it appears that serious game attributes according to the educational perspectives is practiced using various ideas, terms and concepts. Table 3 summarises these categories and the associated attributes. The "incremental learning" attribute category scored the highest percentage of $16 \%$ which indicates that the flow and the structure of learning are important in designing training module. This finding verifies the importance of the flow of training delivery in influencing the process of learning among the users. It is followed by the "scaffolding" serious game attributes which also play big roles in generating an effective learning process. The rest of the serious games are equally important, just in terms of frequency mentioned in articles depends on the purpose of the researcher. Hence, from the findings, it can be justified that serious game attributes are important to enhance the effectiveness of training modules. If one of the attributes is missing, an effective serious game training module cannot be designed.

For Behaviourism theory, the game attributes are focused on the behaviour, especially on the objectivity and activity. In this theory, three main attributes are categorised which are Interaction (SGA01), Reward (SGA02) and Practice and Drill (SGA03). All these elements are the attributes which enhance skills and motivate the user to keep playing the game. Interaction (SGA01) act as the adaptability and manipulability elements allows game changes in response to learner actions. Besides, interaction 
attributes will match the skill levels of learners by matching challenges and possible solutions. The second attribute is practice and drill attributes (SGA03), which provides repetition and constant rehearsal in the learning process. The repeating process of learning will reinforce the learner memory and challenge (GA01) making fun and competition by creating barriers between current state and goal state to keep learner motivation in learning, on the other hand, reward (SGA02) is a must. This attribute will encourage and push learners to progress and make an assessment (GA07) of their learning ability and knowledge gain.

Cognitivism theory is about how to deliver learning process in a progressive manner and the learning is broken into simpler and manageable tasks. There are four attributes related to this theory which are incremental learning (SGA04), linearity (SGA05), attention span (SGA05), and transfer of learning skills (SGA06). Incremental learning (SGA04) is highlighted to become proficient at essential learning first before the master in a complex task. The learning process should be designed from novice stage until master level and be guided learning process using rules and goals (GA04). Linearity attributes (SGA05) is similar to incremental learning (SGA04), but it focuses more on knowledge delivery which means the content of learning. Learning content needs to be relevant and arrange smoothly to keep the learner adapt (GA06) to the learning process. Thus, the learner can easily focus and engage throughout the whole game learning process. These attributes will be supported by linearity and attention span attributes which will transfer knowledge and skills to the learner at the end of the learning process.

Meanwhile, Constructivism theory suggests that learners construct knowledge from their experiences. Hence, to encourage learner in constructing their knowledge scaffolding attributes (SGA08) are implied to the serious game frameworks. The scaffolding attributes (SGA08) will support and help the learners' construct their knowledge through the learning experience. The learning experience can be gained through the curiosity (GA14) and language and communication (GA12). The basic in knowledge delivery is using the comfortable language (GA12) after that create the curiosity (GA14) among the users to keep them engage and lastly give elements of surprises (GA16) to keep their motivation within the learning process. In addition, learners' control attributes (SGA09) will give learner autonomy (GA02) in contributing and volunteering to their knowledge. They can re-examine and re-assess their action during play, which allows them to learn through trial and error.

The concept of learning through experience is implanted by embedding the experiential learning theory, three main attributes found from this theory are [1] accommodating the learner's style (SGA10), [2] scenario-based learning (SGA11) and [3] intermittent feedback (SGA12). Accommodating the learner's style attribute (SGA10) will use to design game module according to the learner preferences (GA03), followed by scenario-based learning (SGA11) which learning environment are designed similar to the real-life situation (GA13). This attribute allows learners to experience similar feelings when dealing with the real situation in the real working environment (GA08). Then, the learner will get prompt feedback of checking their progress of learning (GA15) from the experience through the intermittent feedback attributes (SGA12). 
Table 3. Game attributes categorised according to educational perspectives.

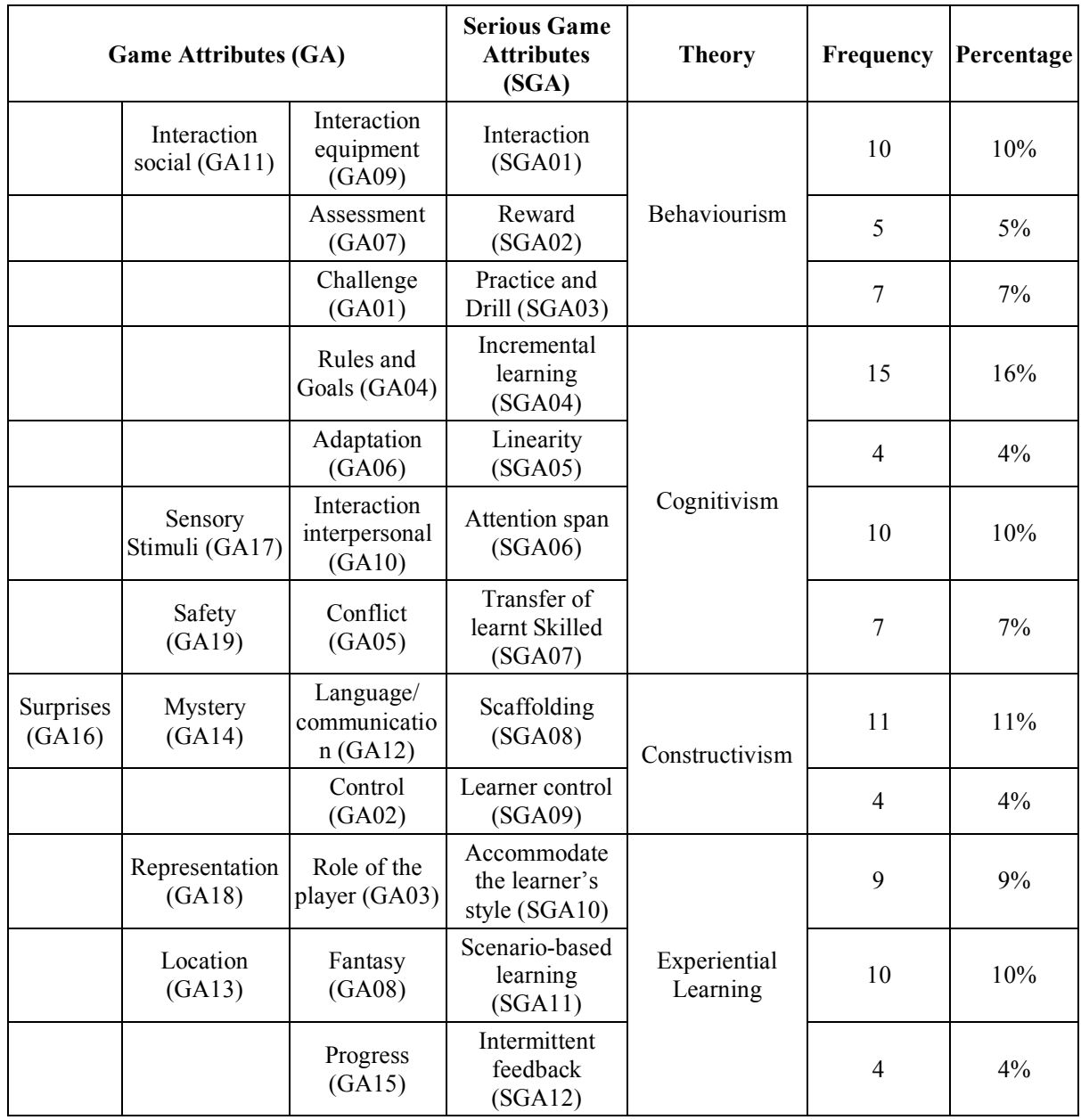

These findings show that previous game attributes' are already interrelated and can be categorised according to the educational perspectives. All twelve attributes will be incorporated in designing effective serious game training modules. Table 4 shows the description on serious game attributes. 
Table 4. The description of serious game attributes [18].

\begin{tabular}{|c|c|}
\hline $\begin{array}{l}\text { Serious Game } \\
\text { Attributes }\end{array}$ & Description summary \\
\hline $\begin{array}{l}\text { Incremental learning } \\
\text { (SGA04) }\end{array}$ & $\begin{array}{l}\text { - Introduce the learning material in a step-by-step manner. } \\
\text { - The essential knowledge needs to conquer before mastering the complex task. } \\
\text { - Each task needs to break down according to the level of achievable. } \\
\text { - The complex task should be divided into the part, to prevent cognitive load } \\
\text { which helps the learner to process the information and recall their prior memory. } \\
\text { - To prevent learner from not engaged with the game as intended, the information } \\
\text { needs to use simple terms which easy to understand. }\end{array}$ \\
\hline $\begin{array}{l}\text { Linearity } \\
\text { (SGA05) }\end{array}$ & $\begin{array}{l}\text { - Learning content delivered in sequence. } \\
\text { - Learning content is relevant with the objective of learning, simple but to the } \\
\text { point. } \\
\text { - The learner needs to immerse within the learning environment. Balancing be- } \\
\text { tween game elements and educational content must be achieved to deliver } \\
\text { knowledge effectively. }\end{array}$ \\
\hline $\begin{array}{l}\text { Attention s } \\
\text { (SGA06) }\end{array}$ & $\begin{array}{l}\text { - The carefully adjusted need to consider in reducing the cognitive process and } \\
\text { short-term memory loads. } \\
\text { - Using low complexity material by combining pictures and text to reduce the } \\
\text { cognitive load. }\end{array}$ \\
\hline $\begin{array}{l}\text { Scaffolding } \\
\text { (SGA08) }\end{array}$ & $\begin{array}{l}\text { - Providing support to the learner until they feel comfortable learning by them- } \\
\text { selves. } \\
\text { - Learner plays important roles in actively construct their knowledge; facilitator } \\
\text { just monitors the progress of learning. } \\
\text { - The learners are encouraged to work with their peers. }\end{array}$ \\
\hline $\begin{array}{l}\text { Practice and drill } \\
\text { (SGA03) }\end{array}$ & $\begin{array}{l}\text { - Trial and error approach requires strengthening new knowledge. } \\
\text { - Repetition and constant rehearsal to reinforce learner memory. }\end{array}$ \\
\hline $\begin{array}{l}\text { Interaction } \\
\text { (SGA01) }\end{array}$ & $\begin{array}{l}\text { - Balancing between elements of fun, interesting and challenging to keep them } \\
\text { remain immersed, attentive and engaged. } \\
\text { - Take avoiding action to prevent learner feel bored and confused during the learn- } \\
\text { ing stage. } \\
\text { - The active learning environment in gathering information to achieve the learning } \\
\text { objective. }\end{array}$ \\
\hline $\begin{array}{l}\text { Learner control } \\
\text { (SGA09) }\end{array}$ & $\begin{array}{l}\text { - Prepared a platform for the learner to create their own learning path, learning } \\
\text { experience and knowledge by exploratory and self-discovery. } \\
\text { - The learner should be able to re-examine and re-assess their actions during play, } \\
\text { which allows them to learn by doing and to learn through experimentation. } \\
\text { - Encourage learner to solve problems using different solutions and perspectives. }\end{array}$ \\
\hline $\begin{array}{l}\text { Intermittent feed- } \\
\text { back (SGA12) }\end{array}$ & $\begin{array}{l}\text { - Feedback is provided informing the learner of progress. } \\
\text { - Quick response and answer should be given to learner. } \\
\text { - Learner ability of learning need to be considered to adjust the } \\
\text { - Adjustment to faster or slower, according to learner ability. }\end{array}$ \\
\hline Reward (SGA02) & $\begin{array}{l}\text { - To encourage and keep learner motivation to keep making progress into their } \\
\text { own learning. } \\
\text { - Avoid over-rewarding to keep effective learning environments. }\end{array}$ \\
\hline $\begin{array}{l}\text { Scenario-based } \\
\text { learning (SGA11) }\end{array}$ & $\begin{array}{l}\text { - Provide a similar learning environment with real life situation and reliable task. } \\
\text { - To give similar feeling when facing a real problem in real life situation. It will } \\
\text { enhance learner ability in control, handling problem and make a decision with real- } \\
\text { istic feeling. }\end{array}$ \\
\hline $\begin{array}{l}\text { Accommodating the } \\
\text { learner's styles } \\
\text { (SGA10) }\end{array}$ & $\begin{array}{l}\text { - Game presentation and well-designed activities should be varied so that they can } \\
\text { accommodate most learner preferences. }\end{array}$ \\
\hline
\end{tabular}




\subsection{Conclusion}

Throughout the systematic literature studies, it has been found that there are nineteen games attributes and twelve serious game attributes that have been used in designing a game. Therefore, in order to create an effective training module, all these game attributes need to be complemented with the theories of learning such as behaviourism, cognitivism, constructivism and experiential learning. On that note, the deductive content analysis was carried out to categories the existing game attributes into the serious game attributes according to the educational perspective. Fourteen articles have been chosen and analysed based on the definition and the purpose of the attributes. There are four existing theories of learning which implied into this framework namely behaviourism, cognitivism, constructivism and experiential learning. Each theory has the purpose and ability to assist effective learning, for example, behaviourism theory is about how to change learner behaviour and approach to attract learner to keep engaging in the learning process. The findings indicated that the existing game attributes are already interrelated with the serious game attributes which have the same roles in the game that is the reason why it can be categorised according to the learning perspectives.

\section{Acknowledgment}

The authors would like to acknowledge the MyBrain15 for the financial support of the study.work.

\section{References}

[1] M. B. Carvalho, Serious Games for Learning: A model and a reference architecture for efficient game development. 2016.

[2] N. Iuppa and T. Borst, "Chapter 23 - Interactive Video and Interactive Television," in Story and Simulations for Serious Games, 2007, pp. 175-183.

[3] Franz-Werner Karner and G. Hartel, "Theory and Taxonomies of Serious Games," 2010.

[4] N. Shiratuddin and S. Zaibon, "Designing user experience for mobile game-based learning," ... Sci. Eng. (i-USEr), ..., pp. 89-94, 2011. https://doi.org/10.1109/iUSEr.2011.6150543

[5] D. Crookall, "Serious games, debriefing, and simulation/gaming as a discipline," Simul. Gaming, vol. 41, no. 6, pp. 898-920, 2010. https://doi.org/10.1177/1046878110390784

[6] J. Kwon and Y. Lee, "Serious games for the job training of persons with developmental disabilities," Comput. Educ., vol. 95, pp. 328-339, 2016. https://doi.org/10.1016/j.compedu. $\underline{2016.02 .001}$

[7] M. Zyda, "From visual simulation to virtual reality to games," Computer (Long. Beach. Calif)., vol. 38, no. 9, pp. 25-32, 2005. https://doi.org/10.1109/MC.2005.297

[8] T. W. Malone, "Toward a Theory of Intrinsically Instruction Motivating," Cogn. Sci., vol. 5, no. 4, pp. 333-369, 1981. https://doi.org/10.1207/s15516709 $\operatorname{cog} 0504 \_2$

[9] M. E. Gredler, "Educational Games and Simulations : A technology in search a (research) paradigm," in Handbook of Research for Educational Communications and Technology, New York: Simon \& Schuster Macmillan, 1996, pp. 521-540.

[10] C. Ong-Flaherty, D. Valencia-Garcia, D. A. Martinez, W. Borges, and L. Summers, "Effectiveness of gaming in creating cultural awareness," Learn. Cult. Soc. Interact., 2017. 
[11] H. Leemkuil, T. De Jong, and S. Ootes, "Review of educational use of games and simulations," 2000.

[12] J. Juul, "The Open and the Closed: Game of emergence and games of progression," Proc. Comput. Game Digit. Cult., pp. 323-329, 2002.

[13] R. Garris, R. Ahlers, and J. E. Driskell, "Games, motivation, and learning: A research and practice model," Simul. Gaming, vol. 33, no. 4, pp. 441-467, 2002. https://doi.org/10.1177/ $\underline{1046878102238607}$

[14] R. Garris and R. Ahlers, "A Research and Practice Model," Simul. Gaming, vol. 33, no. 4, pp. 441-467, 2002. https://doi.org/10.1177/1046878102238607

[15] K. A. Wilson, W. L. Bedwell, E. H. Lazzara, E. Salas, C. S. Burke, J. L. Estock, K. L. Orvis, and C. Conkey, "Relationships Between Game Attributes and Learning Outcomes: Review and Research Proposals," Simul. Gaming, vol. 40, no. 2, pp. 217-266, 2009. https://doi.org/10.1177/1046878108321866

[16] W. L. Bedwell, D. Pavlas, K. Heyne, E. H. Lazzara, and E. Salas, "Toward a taxonomy linking game attributes to learning: An empirical study," Simul. Gaming, vol. 43, no. 6, pp. 729-760, 2012. https://doi.org/10.1177/1046878112439444

[17] C. Conati and X. Zhao, "Building and evaluating an intelligent pedagogical agent to improve the effectiveness of an educational game," Proc. 9th Int. Conf. Intell. user interface - IUI '04, p. 6, 2004.

[18] A. Yusoff, R. Crowder, and L. Gilbert, "Validation of serious games attributes using the technology acceptance model," 2nd Int. Conf. Games Virtual Worlds Serious Appl. VSGAMES 2010, pp. 45-51, 2010. https://doi.org/10.1109/VS-GAMES.2010.7

[19] F. Kohbacher, "The Use of Qualitative Content Analysis in Case Study Research," Forum Qual. Soc. Res., vol. 7, no. 1, p. Art. 21, 2006.

[20] S. Elo and H. Kyngäs, "The qualitative content analysis process," J. Adv. Nurs., vol. 62, no. 1, pp. 107-115, 2008. https://doi.org/10.1111/j.1365-2648.2007.04569.x

[21] B. D. Prasad, "Content Analysis," Res. Methods Soc. Work, no. 2008, pp. 173-193, 2008.

[22] R. Uribe and E. Manzur, "Sample size in content analysis of advertising the case of chilean consumer magazines," Int. J. Advert., vol. 31, no. 4, pp. 907-920, 2012. https://doi.org/10.2501/IJA-31-4-907-920

\section{Authors}

Norhazren Izatie Mohd is a senior lecturer at Quantity Surveying Department, Faculty of Built Environment, Universiti Teknologi Malaysia. She is the member of Royal Institution Surveyor Malaysia (RISM) and Building Information Modelling Research Group (BIMRG). Her research interests are gamification, destructive technology, construction safety, and adult training.

Kherun Nita binti Ali is an Associate Professor at the Faculty of Built Environment, Universiti Teknologi Malaysia. She is the Head of Building Information Center for Digital Innovations and Solutions (BIMCDIS), Faculty of Built Environment, Universiti Teknologi Malaysia, Johor Bahru. Having been also the Head of BIM Research Group in UTM, she is currently active in researches and publications related to Building Information Modelling (BIM). Her recent works with her research team are Enhancing Cost Planning and Control through 5D BIM, BIM Deployment Plan for QS Firms, Facilities Management (7D) BIM, Managing Safety through BIM and GIS BIM. Other research works also include 4.0 IR in higher education and Mobile Augmented Reality 
for teaching and learning Quantity Surveying courses. She is a member of Royal Institutions of Surveyors Malaysia (RISM) BIM Technical Committee since its establishment in 2011.

Ahmad Faiz Azizi Ahmad Fauzi is a 2nd Year postgraduate student from Universiti Teknologi Malaysia. He is currently pursuing his Msc in Philosophy under the department of Quantity Surveying, Faculty of Built Environment and Surveying. Prior to this, he received his Bachelor's degree in Quantity Surveying as well as his Diploma in Quantity surveying from UTM. His primary research interests are in the field of Education Technology, Augmented Reality in Education and Construction related fields.

Shirin Shafiei Ebrahimi is the Postdoctoral Fellow at the Faculty of Education, Universiti Teknologi Malaysia. She is interested in doing research in multidiciplinary areas such as the use of technology in education.

Article submitted 30 June 2018. Resubmitted 18 August 2018. Final acceptance 27 August 2018. Final version published as submitted by the authors. 